\title{
Report on potential sampling biases in the LaMEVE database of global volcanism
}

\author{
Natalia Irma Deligne ${ }^{1 *}$, R. Stephen J. Sparks ${ }^{2}$ and Sarah K. Brown ${ }^{2}$
}

\begin{abstract}
We investigate whether the disproportionate contribution of individual volcanoes in the Large Magnitude Explosive Volcanic Eruption database (LaMEVE) potentially compromises the treatment of LaMEVE as a globally representative database of volcanic activity. We find that $41 \%$ of volcanoes which contribute at least one eruption to LaMEVE only contribute one eruption (10\% of all eruptions), and the six most prolific volcanoes contribute $11 \%$ of eruptions. However, there is no systematic bias with respect to the eruption magnitude or date for volcanoes contributing one eruption. Also, no bias can be discerned for when the smallest or largest eruption at a volcano occurs in its eruptive record. Half of the volcanoes contributing one or more eruptions to the LaMEVE database had their first eruption prior to $36.4 \mathrm{ka}$. We find LaMEVE is representative - while there are well-known issues of eruption under-reporting, LaMEVE is not overly biased by the activity of a few volcanoes.
\end{abstract}

Keywords: LaMEVE, Explosive volcanism, Quaternary, Under-reporting, Individual volcano, Eruptive record

\section{Introduction}

The Large Magnitude Explosive Volcanic Eruption database (LaMEVE) compiles all known explosive Quaternary eruptions with a magnitude (M; Pyle, 2000) or Volcanic Explosivity Index (VEI; Newhall and Self, 1982) of 4 or greater (Crosweller et al., 2012). The database also includes all known Quaternary volcanoes, even if they do not have a qualifying eruption in their current record. Using the terminology introduced in Brown et al. (2014), we refer to volcanoes which contribute at least one eruption to the LaMEVE database as Quaternary Explosive Activity Recorded (QEAR) volcanoes. Under-recording of volcanic eruptions in the LaMEVE and companion databases such as the Smithsonian Institution's Global Volcanism Program (Global Volcanism Program, 2013) is a well-known problem (e.g., Newhall and Self, 1982; Simkin, 1993; Siebert et al., 2010; Brown et al., 2014, Rougier et al., 2016): the further back one goes from the present, the fewer eruptions have been reported, with the recording rate of smaller eruptions decaying more rapidly than for larger eruptions. Various strategies have been taken to both characterise and correct for the incompleteness of the record (e.g., Coles and

\footnotetext{
* Correspondence: N.Deligne@gns.cri.nz

'GNS Science, 1 Fairway Drive, Avalon, Lower Hutt 5010, New Zealand Full list of author information is available at the end of the article
}

Sparks, 2006; Marzocchi and Zaccarelli, 2006; Deligne et al., 2010; Furlan, 2010; Jenkins et al., 2012; Mead and Magill, 2014; Kiyosugi et al., 2015; Rougier et al., 2016) to characterise magnitude-frequency relationships and other properties. However, a potential issue is whether LaMEVE disproportionately "samples" a few volcanoes, introducing biases and potentially compromising its analysis. This report investigates this issue, which has not received previous study.

LaMEVE and companion databases have been used to draw inferences on global or regional activity. An often unstated assumption is that while there is underrecording of eruptions, the existing data are representative of the behaviour of global volcanism. However, Brown et al. $(2014)^{1}$ demonstrated that in the LaMEVE database regions are over and under-representative in the global record. In the LaMEVE database, QEAR volcanoes have a mean of 4.0 eruptions (total number of eruptions / total number of QEAR volcanoes). However, on the high end, QEAR volcanoes in the New Zealand to Fiji region have a mean of 7.1 reported eruptions, whereas on the low end, QEAR volcanoes in both the Africa and Red Sea region and the Kuril Islands region have a mean of 1.4 reported eruptions. Similarly, Kiyosugi et al. $(2015)^{2}$ found that while Japanese eruptions account for $38 \%$ of all LaMEVE eruptions, Japanese 
volcanoes only account for $<4 \%$ of LaMEVE volcanoes. In this report we explore the possibility that individual volcanoes, not just regions, may disproportionately contribute to the global record. If this were the case, then an analysis of global data may in actuality be an analysis of the behaviour of a few volcanoes and hence could be unrepresentative. We examine version 3 of the LaMEVE database, released in September 2015.

\section{Number of eruptions per volcano}

There are 2627 volcanoes in LaMEVE, 480 of which have at least one recorded $M$ and/or VEI $\geq 4$ eruption. Here we will only focus on the subset of volcanoes which contribute at least one eruption to LaMEVE, i.e., QEAR volcanoes.

LaMEVE contains 1927 eruptions, i.e., a mean of 4 eruptions per QEAR volcano. However, individual volcanoes contribute anywhere from 1 to 52 eruptions (Fig. 1). 199 volcanoes (41\%) contribute just one eruption, accounting for $10 \%$ of all eruptions in LaMEVE (Fig. 1). Half of all eruptions in LaMEVE come from volcanoes contributing eight or more eruptions (Fig. 1), and the six most prolific volcanoes (1.25\% of volcanoes with at least one LaMEVE eruption; Fig. 2), contribute at least 27 eruptions each (Fig. 1), account for $11 \%$ all eruptions in LaMEVE.

The uneven contribution of individual volcanoes questions the assumption that LaMEVE is indeed globally representative. Here we examine whether LaMEVE is disproportionately influenced by the behaviour of a few volcanoes.

\section{Volcanoes contributing one eruption}

Here we compare those volcanoes that only record one eruption in LaMEVE with the greater LaMEVE database. We reiterate that eruptions from volcanoes contributing a single eruption account for $10 \%$ of LaMEVE eruptions (Fig. 1), so are unlikely to bias the greater distribution. The magnitude distribution (Fig. 3) and age of eruptions at those volcanoes with only one eruption recorded in LaMEVE is similar to the overall distribution. Only 38 eruptions from volcanoes with only one eruption (19\%) are from $1600 \mathrm{AD}$ onwards, and 93 (47\%) are from the last 10,000 years. In comparison for all eruptions in LaMEVE, 200 (10\%) and 798 (41\%) are from $1600 \mathrm{AD}$ and 10,000 yBP onwards, respectively. These numbers are slightly different, but not enough to suggest a systematic bias towards historic or recent eruptions reported for volcanoes which contributed only a single eruption to LaMEVE. These data show no evidence for major differences about the size or timing of eruptions from volcanoes which contribute a single eruption to LaMEVE.

\section{Eruption sequence}

We investigated whether there might be systematic bias if large eruptions destroy the record of smaller earlier eruptions from the same volcano. There is no discussion of this in the literature, although it would be difficult to establish the occurrence of this in the field. If this does happen, it would result in a systematic bias where smaller eruptions (remembering all eruptions in LaMEVE are large $\geq M 4$ ) are more likely to be recorded if they post-date larger eruptions from the same source, further confounding the already challenging underreporting issue.

At volcanoes contributing two eruptions to LaMEVE, about a quarter are of equal magnitude, and of the remainder it is approximately evenly split between volcanoes where the smaller eruption is older versus where the larger eruption is older (Table 1). For volcanoes contributing three and four eruptions, we examined the

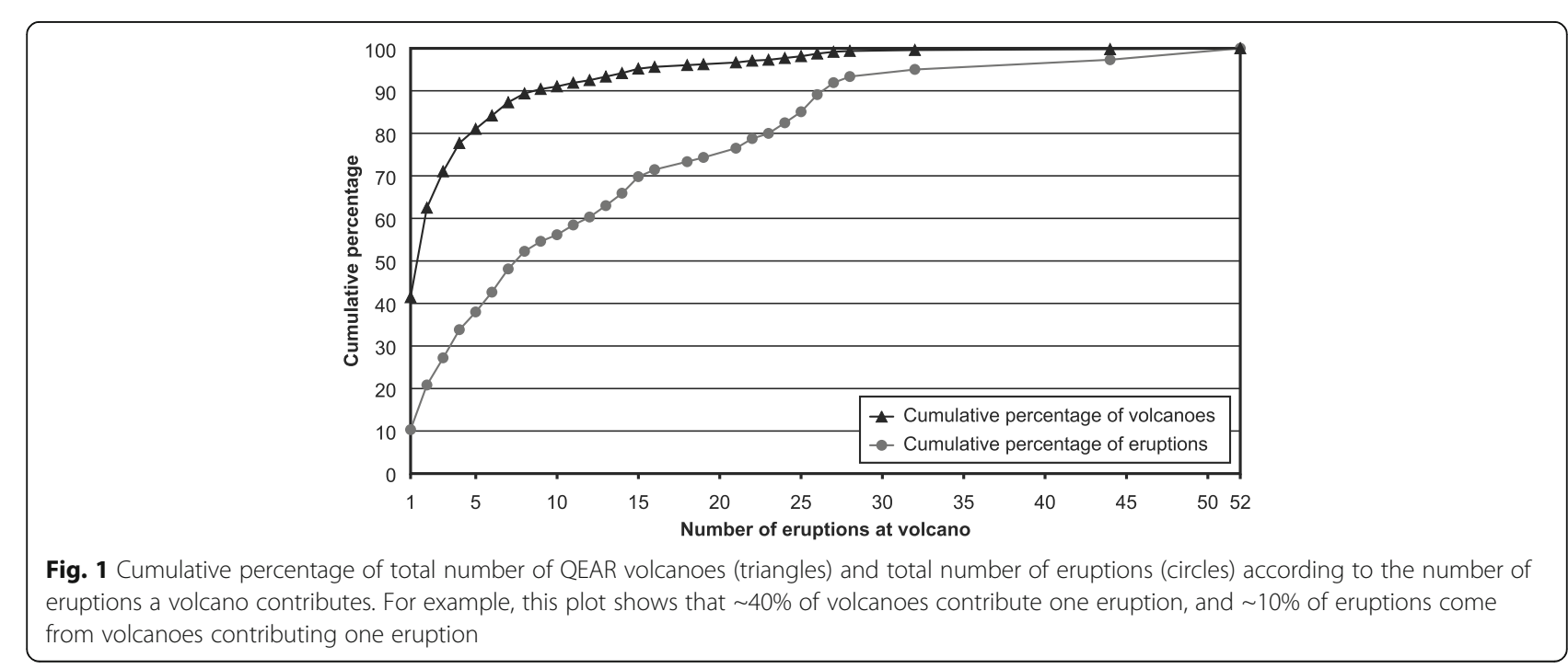




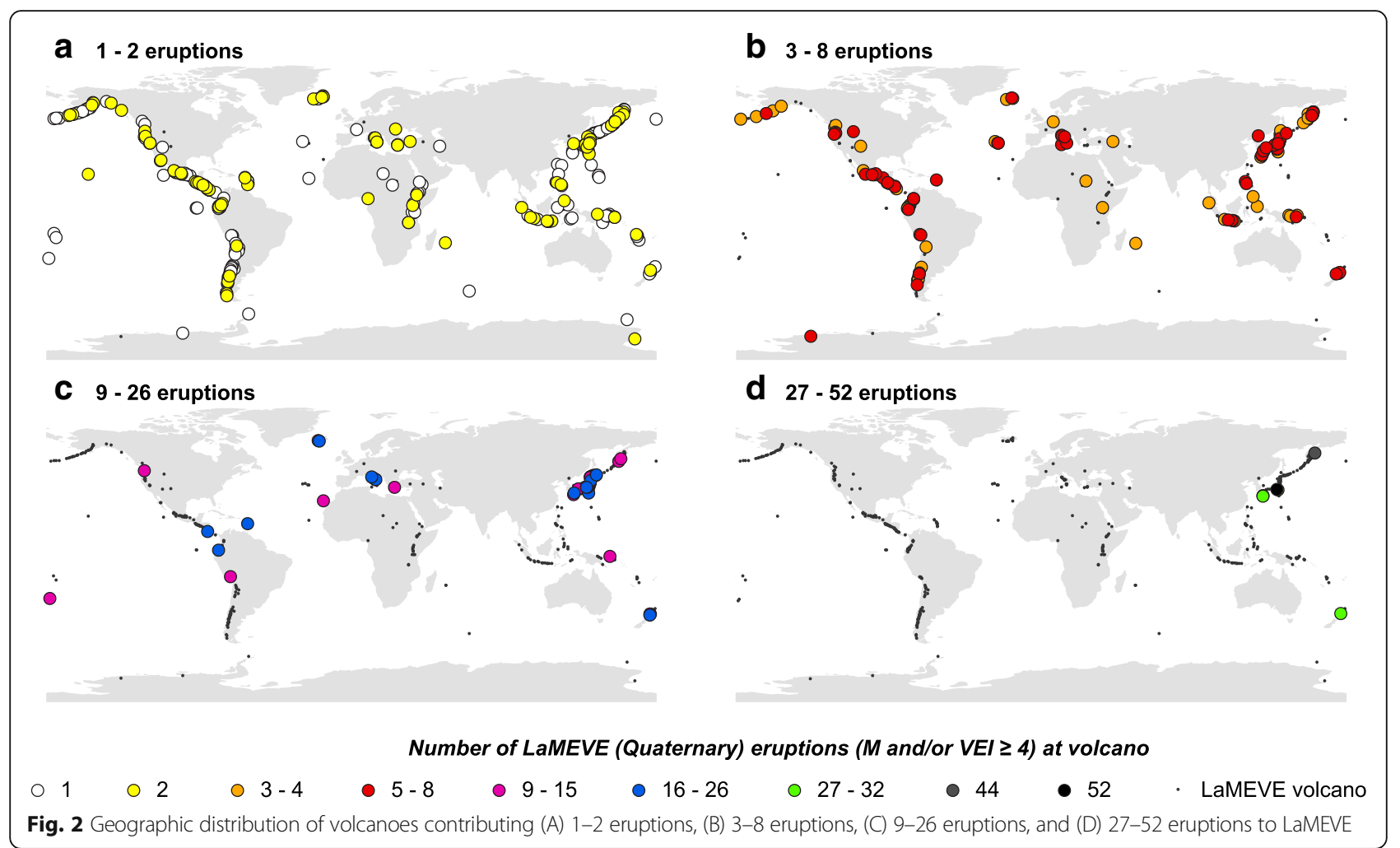

sequence in the individual volcano's record of both the smallest and the largest eruption (Table 1). For cases where there are multiple eruptions of the same magnitude that counts as either the smallest or the largest, the earliest instance of that magnitude is utilized. For example, Calabozos volcano (Chile) had a magnitude 5.2 eruption at $810 \mathrm{ka}$, and magnitude 7.4 eruptions at 800,300 , and $150 \mathrm{ka}$. Thus, in Table 1, in the column of volcanoes with 4 contributing eruptions, Calabozos is one of the 12 volcanoes with the smallest eruption being the oldest, but is not one of the volcanoes where the largest eruption is the youngest. Similarly, Atacazo volcano (Ecuador) had magnitude 4.0 eruptions at 9903 and $6147 \mathrm{yBP}$, a magnitude 5.2 eruption at $5040 \mathrm{yBP}$, and a magnitude 5.3 eruption at $2232 \mathrm{yBP}$. In this case, Atacazo is counted as a volcano which has both its smallest eruption as the oldest, and its largest eruption as the youngest.

At volcanoes contributing three eruptions, there is a greater proportion of largest eruptions which occurred first compared to the smallest eruptions, but it is not a large difference (the limited data preclude robust statistical analysis). At volcanoes contributing four eruptions, the largest and smallest eruptions have similar distributions.

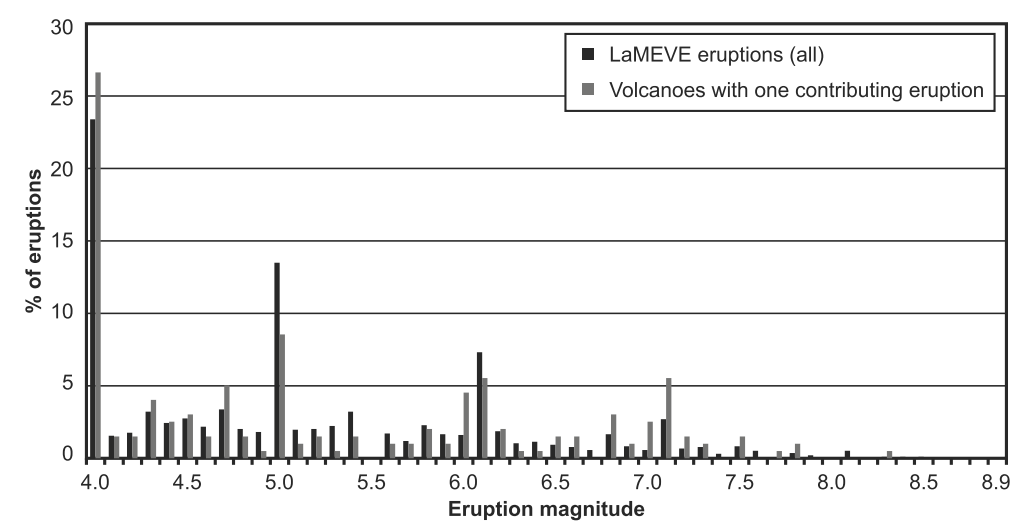

Fig. 3 Histogram of eruption magnitudes in entire LaMEVE database (black) and of volcanoes contributing only one eruption to LaMEVE (grey) as a percentage of eruptions. The spikes at $M$ 4, 5, 6.1, and 7.1 are due to field rounding errors 
Table 1 Examination of when in the eruption sequence the smallest and largest eruption occurred at volcanoes contributing 2-4 eruptions to LaMEVE

\begin{tabular}{llll}
\hline & \multicolumn{4}{l}{ Percentage of total (number of volcanoes) } \\
\cline { 2 - 4 } Number of contributing eruptions at volcano & 2 & 3 & 4 \\
\hline All eruptions same magnitude & $25.7 \%(26)$ & $14.6 \%(6)$ & $3.1 \%(1)$ \\
Smallest eruption oldest & $34.7 \%(35)$ & $31.7 \%(13)$ & $37.5 \%(12)$ \\
Smallest eruption youngest & $39.6 \%(40)$ & $31.7 \%(13)$ & $28.1 \%(9)$ \\
Largest eruption oldest & - & $46.3 \%(19)$ & $34.4 \%(11)$ \\
Largest eruption youngest & - & $22.0 \%(9)$ & $21.9 \%(7)$ \\
\hline
\end{tabular}

Thus, there is no evidence for later larger eruptions systematically destroying the record of earlier smaller eruptions.

\section{By when is LaMEVE globally representative?}

Issues of under-reporting aside, it is useful to determine from what point in time the LaMEVE database is representative of the eruptive history of contributing volcanoes. There is no standard methodology to follow as there might be in the case of under-reporting. However, we note that half of QEAR volcanoes had their earliest contributing eruption before $36.4 \mathrm{ka}$ (Fig. 4). The record of half of QEAR volcanoes largely predates the radiocarbon era (only 46 of the 809 eruptions older than $36.4 \mathrm{ka}$ are dated with radiocarbon methods). Similarly, half of
QEAR volcanoes had their most recent contributing eruption before $6400 \mathrm{yBP}$. The presence of a record of one or more (large) eruptions at a volcano does not mean that individual volcano's record is complete: even volcanoes contributing many eruptions to LaMEVE may have missing eruptions. However, we suggest the future workers use $36.4 \mathrm{ka}$ as a rough guide as to when individual volcanoes do not bias the LaMEVE eruption record.

\section{Conclusions}

The LaMEVE database has substantial under-reporting (incompleteness) issues. At the individual volcano level, $41 \%$ of QEAR volcanoes only contribute one eruption ( $10 \%$ of all eruptions); the most eruptions contributed by a single volcano is 52 eruptions. However, there are no

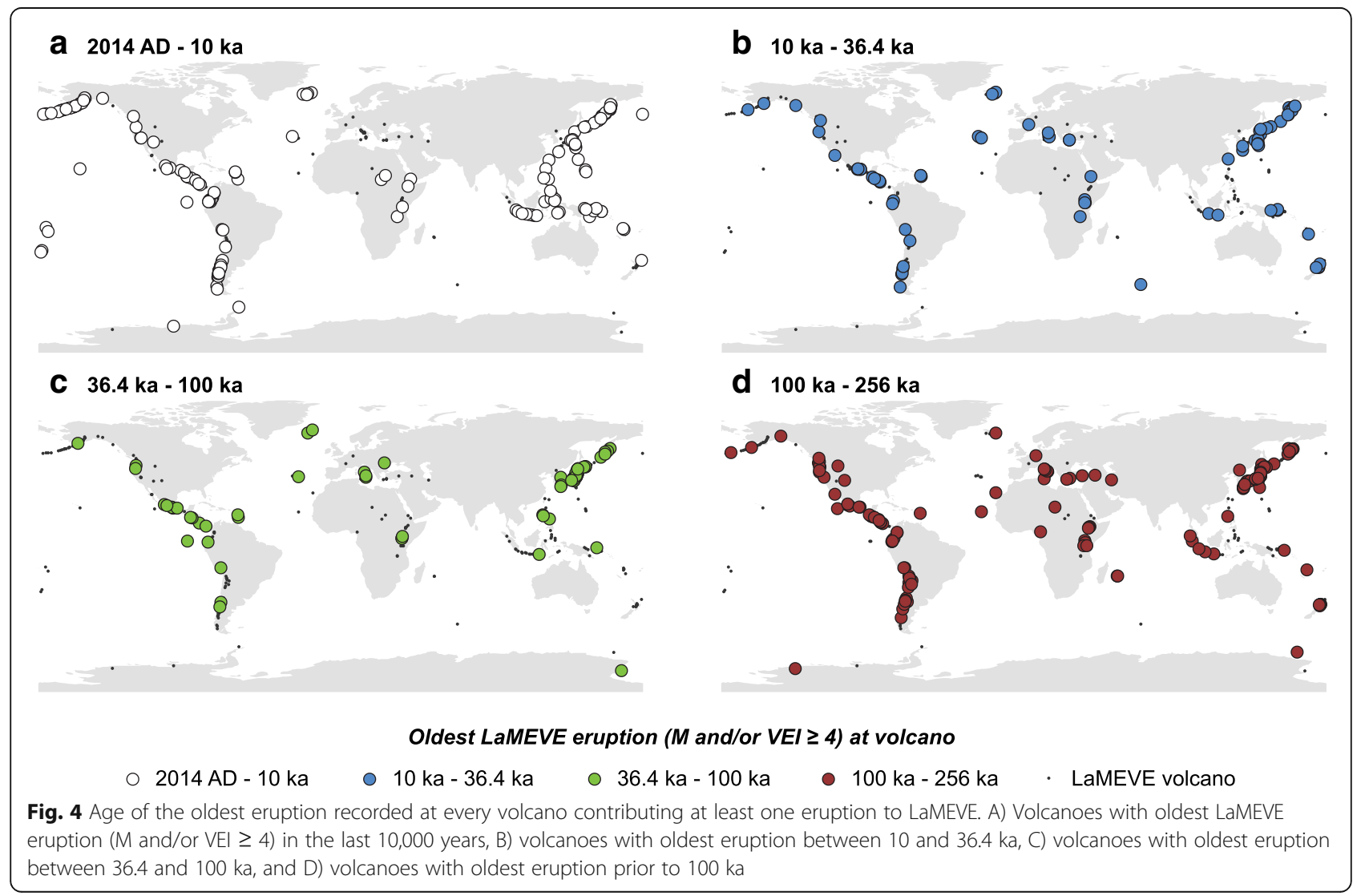


differences in magnitude distribution or eruption date between those volcanoes which contribute only one eruption and those that contribute more than one. We also find that at volcanoes with two, three, or four eruptions there is no bias in eruption size order at individual volcanoes. Finally, half of QEAR volcanoes had their first eruption prior to $36.4 \mathrm{ka}$; this may be an appropriate time to consider the database geographically representative. Overall, we find that LaMEVE does not have systematic biases caused by disproportion contributions by individual volcanoes.

\section{Endnotes}

${ }^{1}$ Brown et al. (2014) used Version 1 of the LaMEVE database.

${ }^{2}$ Kiyosugi et al. (2015) used Version 2 of the LaMEVE database.

\section{Abbreviations}

AD: Anno Domini; ka: kiloannum (thousands of years before present); LaMEVE: Large Magnitude Explosive Volcanic Eruption database;

M: magnitude; QEAR: Quaternary Explosive Activity Recorded; VEl: Volcanic Explosivity Index; yBP: years before present (1950 AD)

\section{Acknowledgements}

The authors acknowledge funding from the Natural Environment Research Council (Global Volcano Model grant) and GNS Science Core Research Programme. Thanks to Kathy Cashman and Jonty Rougier for encouragement and helpful discussions, and Tony Hurst and David Rhoades for early reviews. Comments from editors Graham Leonard and Ilan Kelman and three anonymous reviewers improved the manuscript.

\section{Authors' Contributions}

NID conceived of the study and drafted the manuscript. RSJS helped draft the manuscript. SKB assisted with data acquisition. All authors read and approved the final manuscript.

\section{Competing interest}

There are no competing interests.

\section{Publisher's Note}

Springer Nature remains neutral with regard to jurisdictional claims in published maps and institutional affiliations.

\section{Author details}

${ }^{1}$ GNS Science, 1 Fairway Drive, Avalon, Lower Hutt 5010, New Zealand.

${ }^{2}$ School of Earth Sciences, University of Bristol, Wills Memorial Building,

Queens Road, Bristol BS8 1RJ, UK.

Received: 17 December 2015 Accepted: 18 May 2017

Published online: 25 May 2017

\section{References}

Brown SK, Crosweller HS, Sparks RSJ, Cottrell E, Deligne NI, Guerrero NO, et al. Characterisation of the quaternary eruption record: analysis of the large magnitude explosive volcanic eruptions (LaMEVE) database. J Appl Volcanol. 2014;3:5.

Coles S, Sparks RSJ. Extreme value methods for modelling historical series of large volcanic magnitudes. In: Mader HM, Coles SG, Connor CB, Connor LD, editors. Statistics in Volcanology, vol. 1. Geological Society of London: Special Publication of IAVCEl; 2006. p. 47-56.

Crosweller HS, Arora B, Brown SK, Cottrell E, Deligne NI, Guerrero NO, et al. Global database on large magnitude explosive volcanic eruptions (LaMEVE). J Appl Volcanol. 2012;1(4):1-1310.1186/2191-5040-1-4.
Deligne NI, Coles SG, Sparks RSJ. Recurrence rates of large explosive volcanic eruptions. J Geophys Res. 2010;115:B06203.

Furlan C. Extreme value methods for modelling historical series of large volcanic magnitudes. Stat Model. 2010;10(2):113-32.

Global Volcanism Program (2013) Volcanoes of the World, v. 4.5.5. Venzke E (ed). Smithsonian Institution. http://dx.doi.org/10.5479/si.GVP.VOTW4-2013. Accessed 05 Apr 2017.

Jenkins S, Magill C, McAneney J, Blong R. Regional ash fall hazard I: a probabilistic assessment methodology. Bull Volcanol. 2012;74(7):1699-712.

Kiyosugi K, Connor C, Sparks RSJ, Crosweller HS, Brown SK, Siebert L, et al. How many explosive eruptions are missing from the geologic record? Analysis of the quaternary record of large magnitude explosive eruptions in Japan. J Appl Volcanol. 2015;4:17.

Marzocchi W, Zaccarelli L. A quantitative model for the time-size distribution of eruptions. J Geophys Res. 2006;111:B04204.

Mead S, Magill C. Determining change points in data completeness for the Holocene eruption record. Bull Volcanol. 2014;76:874.

Newhall CG, Self S. The volcanic Explosivity Index (VEI) - an estimate of explosive magnitude for historical volcanism. J Geophys Res Oceans Atmos. 1982; 87(C2):1231-8

Pyle DM. Sizes of volcanic eruptions. In: Sigurdsson H, Houghton BF, McNutt SR, Rymer H, Stix J, editors. Encyclopedia of volcanoes. London: Academic Press; 2000.

Rougier J, Sparks RSJ, Cashman KV. Global recording rates for large eruptions. J Appl Volcanol. 2016;5:11.

Siebert L, Simkin T, Kimberly P. Volcanoes of the world, 3rd ed.Berkeley: Smithsonian Institution, University of California Press; 2010.

Simkin T. Terrestrial volcanism in space and time. Annu Rev Earth Planet Sci. 1993;21:427-52.

\section{Submit your manuscript to a SpringerOpen ${ }^{\circ}$ journal and benefit from:}

- Convenient online submission

- Rigorous peer review

- Open access: articles freely available online

- High visibility within the field

- Retaining the copyright to your article

Submit your next manuscript at $\boldsymbol{\nabla}$ springeropen.com 